\title{
Augmented reality navigation in spine surgery: a systematic review
}

\author{
Gustav Burström $^{1,2}$ (D) $\cdot$ Oscar Persson ${ }^{1,2} \cdot$ Erik Edström $^{1,2} \cdot$ Adrian Elmi-Terander $^{1,2}$
}

Received: 29 October 2020 / Accepted: 6 January 2021 / Published online: 28 January 2021

(C) The Author(s) 2021

\begin{abstract}
Background Conventional spinal navigation solutions have been criticized for having a negative impact on time in the operating room and workflow. AR navigation could potentially alleviate some of these concerns while retaining the benefits of navigated spine surgery. The objective of this study is to summarize the current evidence for using augmented reality (AR) navigation in spine surgery.

Methods We performed a systematic review to explore the current evidence for using AR navigation in spine surgery. PubMed and Web of Science were searched from database inception to November 27, 2020, for data on the AR navigation solutions; the reported efficacy of the systems; and their impact on workflow, radiation, and cost-benefit relationships.

Results In this systematic review, 28 studies were included in the final analysis. The main findings were superior workflow and non-inferior accuracy when comparing AR to free-hand $(\mathrm{FH})$ or conventional surgical navigation techniques. A limited number of studies indicated decreased use of radiation. There were no studies reporting mortality, morbidity, or cost-benefit relationships. Conclusions AR provides a meaningful addition to FH surgery and traditional navigation methods for spine surgery. However, the current evidence base is limited and prospective studies on clinical outcomes and cost-benefit relationships are needed.
\end{abstract}

Keywords Accuracy $\cdot$ Augmented reality $\cdot$ Pedicle screw $\cdot$ Systematic review $\cdot$ Surgical navigation $\cdot$ Virtual path tracking

\section{Introduction}

Compared to conventional free-hand (FH) surgical techniques, computer-assisted surgery (CAS) has been shown to improve pedicle screw placement accuracy and is gaining use in spine surgery [41]. Despite the known advantages of CAS, implementation in spine surgery has been slower than corresponding cranial applications, partly due to the relatively complicated and time-consuming setup in spine. A negative impact on OR time and workflow is the most common concern among spine surgeons regarding CAS systems [25]. In conventional navigation, the surgeon must look away from the surgical field into a dedicated navigation screen to verify

This article is part of the Topical Collection on Spine - Other

Previous presentations No previous presentation.

Gustav Burström

gustav.burstrom@ki.se

1 Department of Clinical Neuroscience, Karolinska Institutet, Stockholm, Sweden

2 Department of Neurosurgery, Karolinska University Hospital, 17176 Stockholm, Sweden anatomical positions and landmarks on a virtual 3D representation.

An ideal CAS solution allows for the visualization of the anatomy without obscuring the surgical field or distracting the surgeon. In augmented reality (AR) navigation solutions, the real environment and virtual information is presented in the same field of view [3]. The AR view is an augmentation of reality with virtual content to improve surgical workflow and promote increased adoption of navigation technologies in spine surgery [27].

Current research on AR navigation is at an early stage [28]. One of the first published clinical papers on AR navigation in spine surgery was authored by $\mathrm{Wu}$ et al., and explored the use of a projector to display the underlying spine anatomy on the surface of the patient [47]. The system was qualitatively reviewed by surgeons in three patients but further studies on this system have not been published. The first published work on an AR application later brought into clinical trials was performed by Elmi-Terander et al. [22]. This system relied on an AR-enhanced video feed of the surgical field, shown on a monitor. Several preclinical and clinical trials using the same AR approach have followed [2, 8, 16, 17, 19-21, 38]. Later studies have focused on AR systems presented on headmounted displays instead of monitors, providing AR directly 
in the surgeon's field of view [31, 42, 46]. However, the potential benefits of using AR in spine surgery in terms of accuracy, radiation doses, workflow, and cost-benefit have yet to be determined. Previous systematic reviews have partially included spine surgery while focusing on AR surgery in general; however, a focused systematic review of AR navigation for spine surgery is lacking $[27,34,43]$.

This study aims to present a systematic review of the current state of AR navigation in spine surgery. We describe the currently available AR navigation interfaces and patient tracking solutions, and summarize the reported accuracies and impact on clinical outcomes, as well as the impact on workflow, radiation, and cost-benefit relationships. Focusing on clinically relevant publications, only studies on patients, cadavers, or cadaveric vertebral models are included.

\section{Methods}

\section{Search methods and selection process}

A systematic search was performed in two databases, "PubMed" and "Web of Science." All studies written in English from database inception until 27th of November 2020 were included. A combination of the words and phrases (augmented reality), and ((spine or spinal) surgery) or (pedicle screw), was used. Each included study was screened for additional cited and relevant studies to be included in the systematic review. Based on title and abstract, an eligibility screening was performed by two authors. Next, a selection of eligible studies was performed by analyzing full texts. The review followed the Preferred Reporting Items on Systematic Reviews and Meta-analysis (PRISMA) guidelines [29].

\section{Eligibility criteria and selection process}

Inclusion criteria were (1) studies in English; (2) minimum evidence level V using Oxford Centre for Evidence-Based Medicine 2011 Levels of Evidence; (3) AR was used in spine surgery on patients, cadavers, or cadaveric vertebral models; and (4) surgical outcome was reported. Exclusion criteria were (1) review articles or meeting abstracts; (2) articles lacking an available full text; (3) AR used for surgery other than spinal, or solely for biopsies or non-surgical injections; (4) proof-of-concept studies or case-reports reporting single attempts; and (5) studies reporting only qualitative feedback from surgeons.

\section{Data extraction and quality assessment}

Data extraction consisted of author and year of study, type of study subjects, AR interface type, patient tracking solution, and the main findings. Main findings were further sub- divided into accuracy assessment, radiation dose, and costbenefit analyses. The quality of the available evidence was graded according to the GRADE criteria [24].

\section{Results}

A total of 28 studies were included, as shown in Fig. 1 and detailed in Table 1. The PubMed and Web of science searches returned 100 and 96 results, respectively. After removal of duplicates, 127 studies remained. Based on title and abstracts, 41 studies were selected for inclusion, and full-text versions were obtained. Thirteen studies were excluded from the final analysis since they did not meet the inclusion criteria or met exclusion criteria. After carefully reviewing the bibliography of each of the papers, one additional citation was included. The majority of studies (19 out of 28 ) concerned pedicle screw placement or pedicle cannulation in thoracolumbar levels (Table 1).

\section{Interfaces}

Four main types of AR user interfaces were identified among the included studies. The two most common were monitor-based (Monitor-AR, 10 studies) and head-mounted displays (HMD-AR, 12 studies). Monitor-AR typically consisted of video cameras, imbedded in the $\mathrm{C}$-arm, aimed at the surgical field and a separate monitor displaying the video feed with AR overlay (Fig. 2). HMD-AR, on the other hand, was worn on the surgeon's head as goggles, and the AR view was overlaid directly in the surgeon's field of view (Fig. 3). Microscope-based AR interfaces (Microscope-AR, 4 studies) projected pre-defined AR objects in the microscope view during microsurgery (Fig. 4). Projector-based AR interfaces (Projector-AR, 2 studies) provided holographic AR overlays on glass-screens situated between the surgical area and the surgeon (Fig. 5).

The heterogeneity among reported study outcomes did not allow meta-analytical comparisons between the AR interfaces. Accuracy measurements providing the distance between the planned trajectories and the final device position (i.e., technical accuracy) were provided in a majority of Monitor-, Projector-, and HMD-AR studies. However, there was no consensus on 1D, 2D, or 3D translational measurements or the anatomical plane when reporting 1D or 2D measurements. No study using Microscope-AR provided technical accuracy. Target registration error (TRE), describing the calculated reliability, or quality, of the patient registration in the navigation software, was reported instead. Since TRE is only one out of many parts contributing to the final technical accuracy, a direct comparison is not possible. 
Table 1 Studies on augmented reality navigation in spine surgery

\begin{tabular}{|c|c|c|c|c|c|c|c|}
\hline Authors & Year & Study type & Study subjects & Procedure & Spine segments & Interface type & Patient registration/tracking type \\
\hline Abe et al. [1] & 2013 & Cohort & $\begin{array}{c}\text { Phantom }+ \\
\text { patients }\end{array}$ & Vertebroplasty & Thoracolumbar & HMD & Preop CT and fluoroscopy/DRF \\
\hline $\begin{array}{l}\text { Elmi-Terander } \\
\text { et al. [22] }\end{array}$ & 2016 & Controlled & Cadaver & Pedicle screw & Thoracolumbar & Monitor & Intraop CBCT/skin markers \\
\hline Ma et al. [33] & 2017 & Cohort & Phantom & Pedicle screw & Lumbar & Projector & Ultrasound/DRF \\
\hline $\begin{array}{l}\text { Elmi-Terander } \\
\text { et al. [21] }\end{array}$ & 2018 & Cohort & Cadaver & Pedicle screw & Thoracolumbar & Monitor & Intraop CBCT/skin markers \\
\hline Auloge et al. [2] & 2019 & $\mathrm{RCT}$ & Patients & Vertebroplasty & Thoracolumbar & Monitor & Intraop CBCT/skin markers \\
\hline Burström et al. [8] & 2019 & Cohort & Cadaver (pig) & Pedicle screw & Thoracolumbar & Monitor & Intraop CBCT/skin markers \\
\hline Carl et al. [10] & 2019 & Cohort & Patients & Multiple & All segments & Microscope & Intraop CT/DRF \\
\hline Carl et al. [11] & 2019 & Cohort & Patients & Tumor & Cervical, thoracic & Microscope & Intraop CT/DRF \\
\hline Carl et al. [13] & 2019 & Cohort & Patients & Tumor & All segments & Microscope & Intraop CT/DRF \\
\hline $\begin{array}{l}\text { Elmi-Terander } \\
\text { et al. [20] }\end{array}$ & 2019 & Cohort & Patients & Pedicle screw & Thoracolumbar & Monitor & Intraop CBCT/skin markers \\
\hline Gibby et al. [23] & 2019 & Cohort & Phantom & Pedicle screw & Lumbar & $\begin{array}{l}\text { HMD } \\
\text { (HoloLens) }\end{array}$ & $\begin{array}{l}\text { Manual adjustments/surface } \\
\text { tracking }\end{array}$ \\
\hline $\begin{array}{l}\text { Liebmann et al. } \\
{[30]}\end{array}$ & 2019 & Cohort & Phantom & Pedicle screw & Lumbar & $\begin{array}{l}\text { HMD } \\
\text { (HoloLens) }\end{array}$ & Pointer/surface tracking \\
\hline Liu et al. [31] & 2019 & Controlled & Phantom & Pedicle screw & Lumbar & $\begin{array}{l}\text { HMD } \\
\text { (HoloLens) }\end{array}$ & $\begin{array}{l}\text { Two groups: CT or manual/surface } \\
\text { tracking }\end{array}$ \\
\hline Molina et al. [36] & 2019 & Cohort & Cadaver & Pedicle screw & Thoracolumbar & HMD & Intraop CT/DRF \\
\hline Urakov et al. [42] & 2019 & Controlled & Cadaver & Pedicle screw & Thoracolumbar & $\begin{array}{l}\text { HMD } \\
\text { (HoloLens) }\end{array}$ & $\begin{array}{l}\text { Manual adjustments/surface } \\
\text { tracking }\end{array}$ \\
\hline $\begin{array}{l}\text { Wanivenhaus et al. } \\
\text { [45] }\end{array}$ & 2019 & Controlled & Phantom & Rod bending & Lumbosacral & $\begin{array}{l}\text { HMD } \\
\text { (HoloLens) }\end{array}$ & Pointer/surface tracking \\
\hline Wei et al. [46] & 2019 & $\mathrm{RCT}$ & Patients & Kyphoplasty & Thoracolumbar & $\begin{array}{l}\text { HMD } \\
\quad \text { (HoloLens) }\end{array}$ & $\begin{array}{l}\text { Manual adjustments/surface } \\
\text { tracking }\end{array}$ \\
\hline Edstrom et al. [17] & 2020 & Cohort & Patients & Pedicle screw & Thoracolumbar & Monitor & Intraop CBCT/skin markers \\
\hline Edstrom et al. [16] & 2020 & Cohort & Patients & Pedicle screw & Thoracolumbar & Monitor & Intraop CBCT/skin markers \\
\hline $\begin{array}{l}\text { Elmi-Terander } \\
\text { et al. [19] }\end{array}$ & 2020 & Controlled & Patients & Pedicle screw & Thoracolumbar & Monitor & Intraop CBCT/skin markers \\
\hline Muller et al. [37] & 2020 & Controlled & Phantom/Cadaver & Pedicle screw & Lumbar & $\begin{array}{l}\text { HMD } \\
\text { (HoloLens) }\end{array}$ & Fluoroscopy/DRF \\
\hline Edström et al. [18] & 2020 & Controlled & Patients & Pedicle screw & Thoracolumbar & Monitor & Intraop CBCT/skin markers \\
\hline Peh et al. [38] & 2020 & Controlled & Cadaver & Pedicle screw & Thoracolumbar & Monitor & Intraop CBCT/skin markers \\
\hline Carl et al. [12] & 2020 & Cohort & Patients & Multiple & All segments & Microscope & Intraop CT/DRF \\
\hline Dennler et al. [14] & 2020 & Controlled & Phantom & Pedicle screw & Lumbar & $\begin{array}{l}\text { HMD } \\
\text { (HoloLens) }\end{array}$ & $\begin{array}{l}\text { Manual adjustments/surface } \\
\text { tracking }\end{array}$ \\
\hline Molina et al. [35] & 2020 & Cohort & Cadaver & Pedicle screw & $\begin{array}{l}\text { Thoracic and } \\
\text { lumbosacral }\end{array}$ & HMD & Intraop CT/DRF \\
\hline $\begin{array}{l}\text { Siemionow et al. } \\
\quad[40]\end{array}$ & 2020 & Cohort & Cadaver & Pedicle screw & Thoracolumbar & Projector & Intraop CT/DRF \\
\hline $\begin{array}{l}\text { von Atzigen et al. } \\
\text { [44] }\end{array}$ & 2020 & Cohort & Phantom & Rod bending & Lumbosacral & $\begin{array}{l}\text { HMD } \\
\text { (HoloLens) }\end{array}$ & Surface tracking \\
\hline
\end{tabular}

$C T$ computed tomography, $D R F$ dynamic reference frame, $H M D$ head-mounted display, Preop preoperative, $R C T$ randomized controlled trial

\section{Patient registration and tracking}

Patient registration was performed in three principal ways. Ten studies used intraoperative cone beam computed tomography (CBCT), with simultaneous patient position registration, to align radiological imaging with the patient in the operating room (OR) $[2,8,16-22,38]$. Eight studies used intraoperative computed tomography (CT) with simultaneous patient position registration $[10-13,32,35$, $36,40]$. The remaining studies used preoperative CT in some fashion, either coupled to manual alignment with hand gestures, fluoroscopy, or custom-made pointers to register bone surfaces in the OR $[1,23,30,33,37,42$, $45,46]$. 
Fig. 1 Flowchart of the systematic research in "PubMed" and "Web of Science"

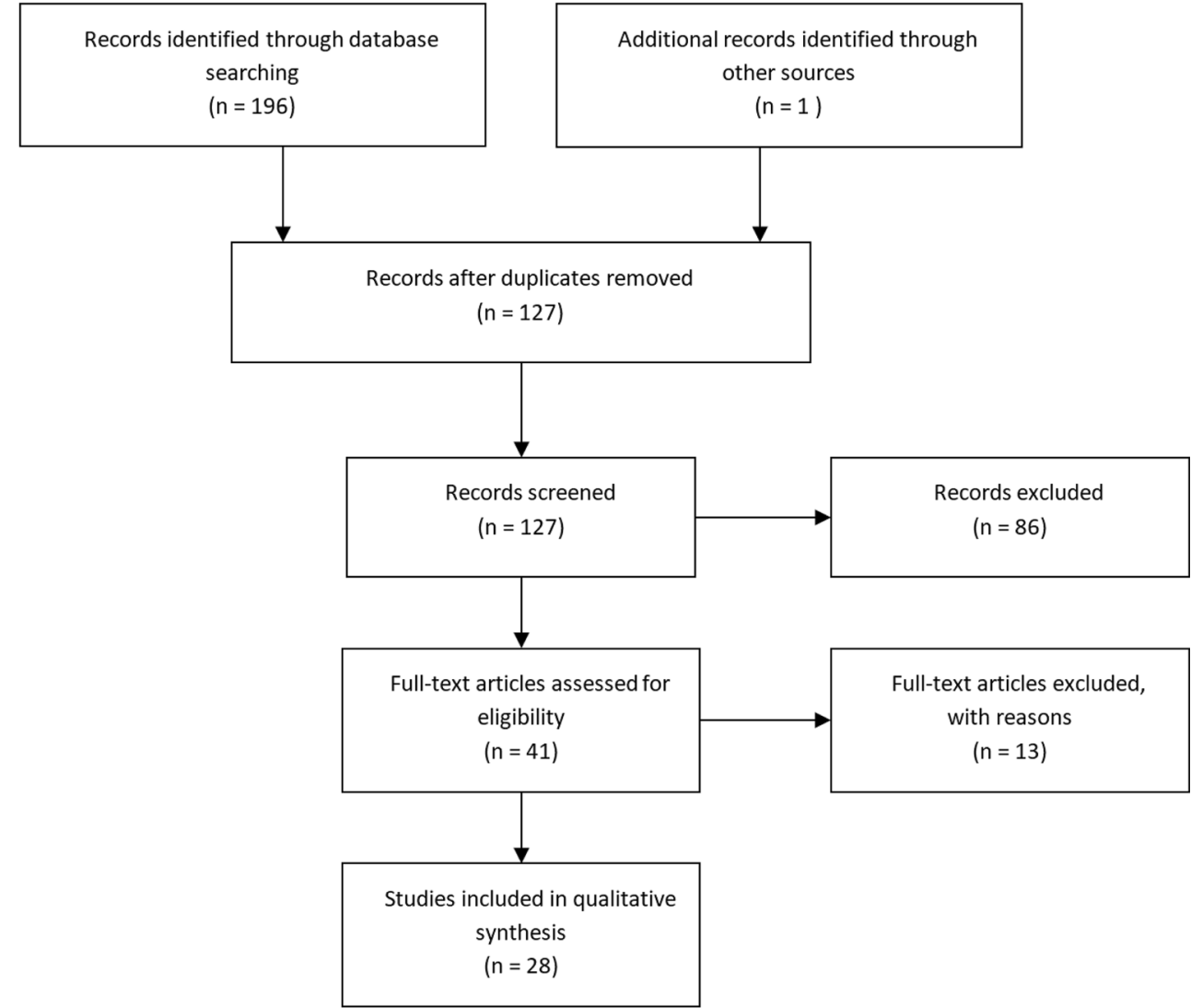

Overall, four different patient tracking technologies were used. All technologies relied on optical tracking, where optical or infrared cameras were used. Ten studies used optical markers attached to the patients' skin, surrounding the surgical field [2, 8, 16-22, 38]. Nine studies used a dynamic reference frame usually attached to a spinous process or firmly attached to the patients' skin [1, 10-13, 35-37, 40]. Seven studies relied on surface tracking combined with manual adjustments, where the camera system identified patients' surface anatomy or exposed spinal anatomy $[14,23,30,31,42,45,46]$. One study relied on direct surface matching and tracking without the need for manual adjustments [44]. One study relied on ultrasonography to match internal bone surface anatomy to preoperative imaging [33].

\section{Accuracy and clinical outcomes}

Seven studies compared AR to FH with or without fluoroscopy for pedicle screw placement [14, 18, 19, 22, 32, 38, 42]. The study with the highest available evidence grade was performed by Elmi-Terander et al., comparing a prospective cohort of 20 patients to 20 retrospectively enrolled patients where FH with or without fluoroscopy had been used [19]. The AR and FH groups were matched based on diagnosis and proportions of thoracic vs. lumbar screws. The study found a higher accuracy in the AR vs. the FH group (AR: $93.9 \%$ vs. FH: $89.6 \%, p<0.05)$. The same authors used Gertzbein grading to compare AR-navigated and $\mathrm{FH}$ pedicle screw accuracies without fluoroscopic guidance in a cadaveric setup where AR had a superior accuracy (AR: $85 \%$ vs. FH: $64 \%, p<0.05$ )
Fig. 2 Example of a monitorbased augmented reality (AR) system. To the right, the operating room setup during surgery is seen. To the right, a depiction of the AR interface as seen by the surgeon. The figure is an unmodified reproduction of the work of ElmiTerander et al., published in the Spine [20]

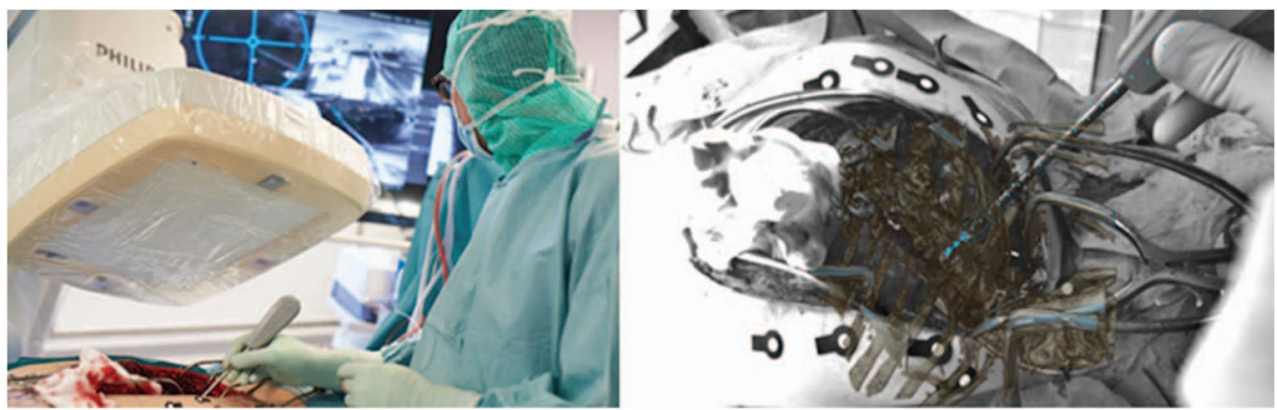


Fig. 3 Example of an augmented reality (AR) system using a headmounted display. Multiple intraoperative views are depicted, with the AR overlay

superimposed as viewed by the surgeon. The figure is an unmodified reproduction of the work of Wei et al., published in the Journal of Orthopaedic Surgery and Research [46]. It is reproduced under the Creative Commons Attribution License (http://creativecommons.org/ licenses/by/4.0/)

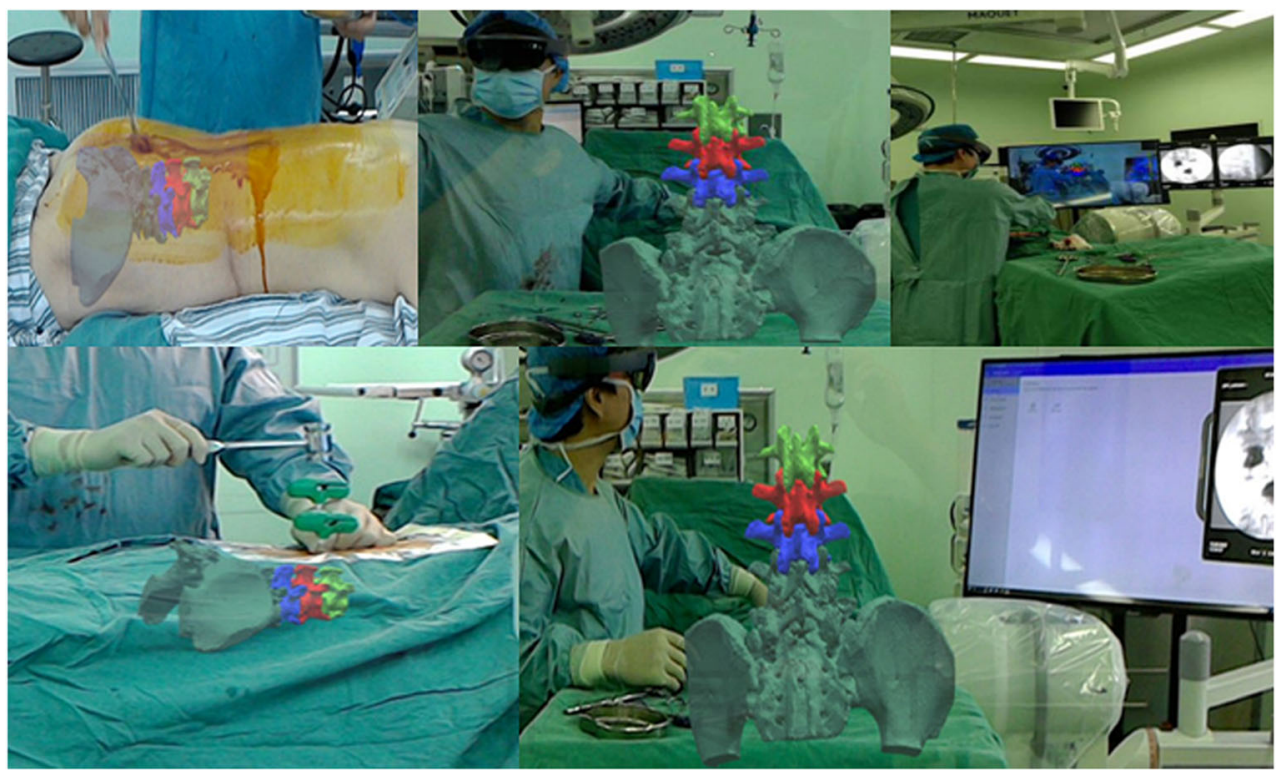

[22]. Peh et al. performed a cadaveric study, using minimally invasive techniques, comparing $\mathrm{AR}$ to $\mathrm{FH}$ with fluoroscopy [38]. Overall, no significant difference was found between the groups (AR: $94 \%$ vs. FH: $88 \%, p=0.50$ ) but in secondary reported outcomes the trend was towards increased accuracy using AR. Although no power analysis was provided, the authors discussed that the study could have been underpowered. Comparing HMD-AR to FH with fluoroscopy, Urakov et al. observed fewer major breaches in the FH group (HMDAR: $36.8 \%$ vs. FH: $0 \%$ major breaches) [42]. However, the study was small and carried no statistical analysis. Liu et al. compared HMD-AR to fluoroscopy-guided FH pedicle screws in a study on phantom models [32]. No significant difference was found (HMD-AR: 94\% vs. FH: 100\%, $p=$ 0.106). Dennler et al. compared HMD-AR to FH in two groups of surgeons: novice or experienced spine surgeons [14]. They found no difference in accuracy between HMD$\mathrm{AR}$ and $\mathrm{FH}$ in the experienced spine surgeon group, but superior accuracy for novice surgeons using HMD-AR ( $p=$ 0.044).
Fig. 4 Example of a microscopebased augmented reality system. a The operating room setup during patient registration using an intraoperative $\mathrm{CT}$ (black arrows) and a dynamic reference frame (white arrows). b The operating room setup is seen during surgery with continuous patient tracking (white arrows) and microscope tracking (black arrows). c Active surgery is seen with augmented reality views on monitors in the background, mirroring what is seen in the microscope. The figure is an unmodified reproduction of the work of Carl et al., published in the European Spine Journal [13]

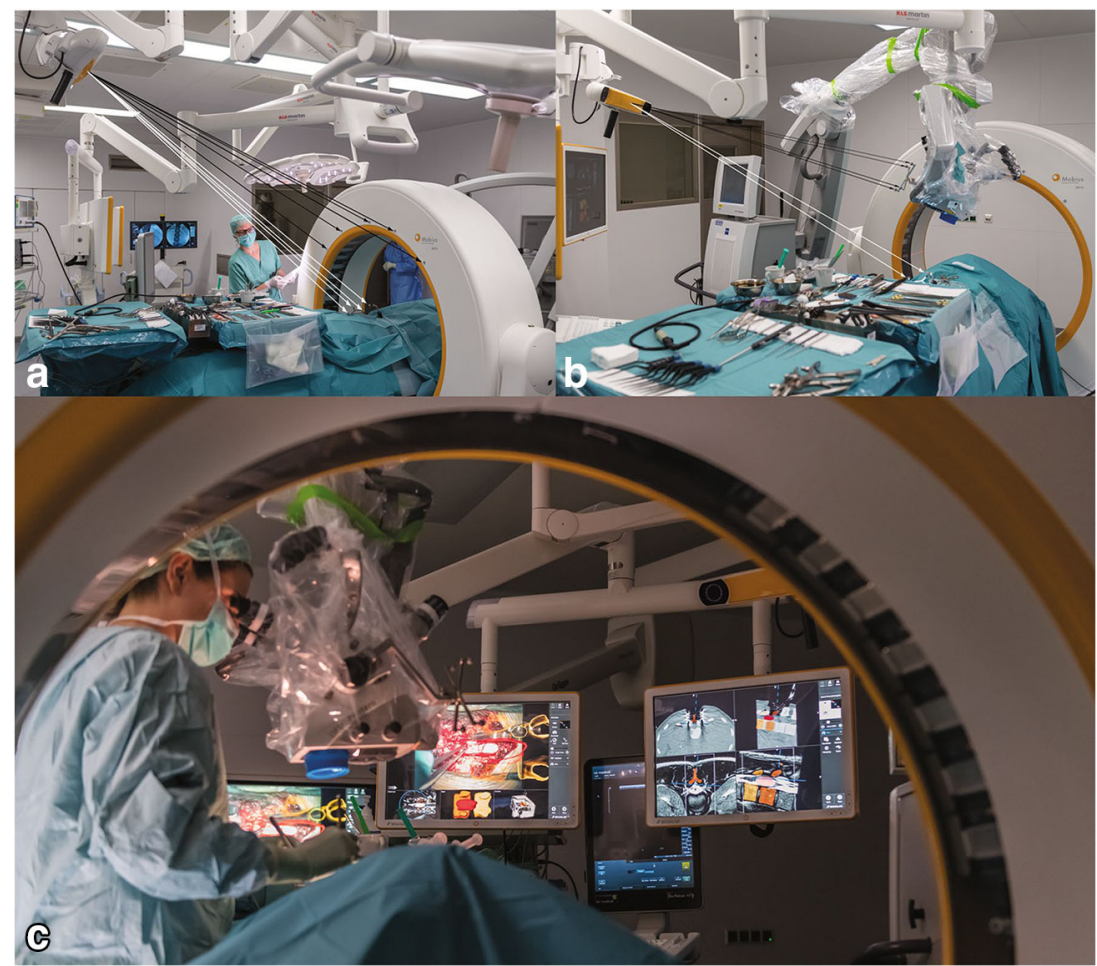


Fig. 5 Example of a holographic visualization of augmented reality. In a, an overview of the setup. In $\mathbf{b}$, the tracked drilling instrument. In $\mathbf{c}$, the interface as seen by the surgeon. The figure is an unmodified reproduction from the work of Ma et al., published in the International Journal of Computer Assisted Radiology and Surgery [33]
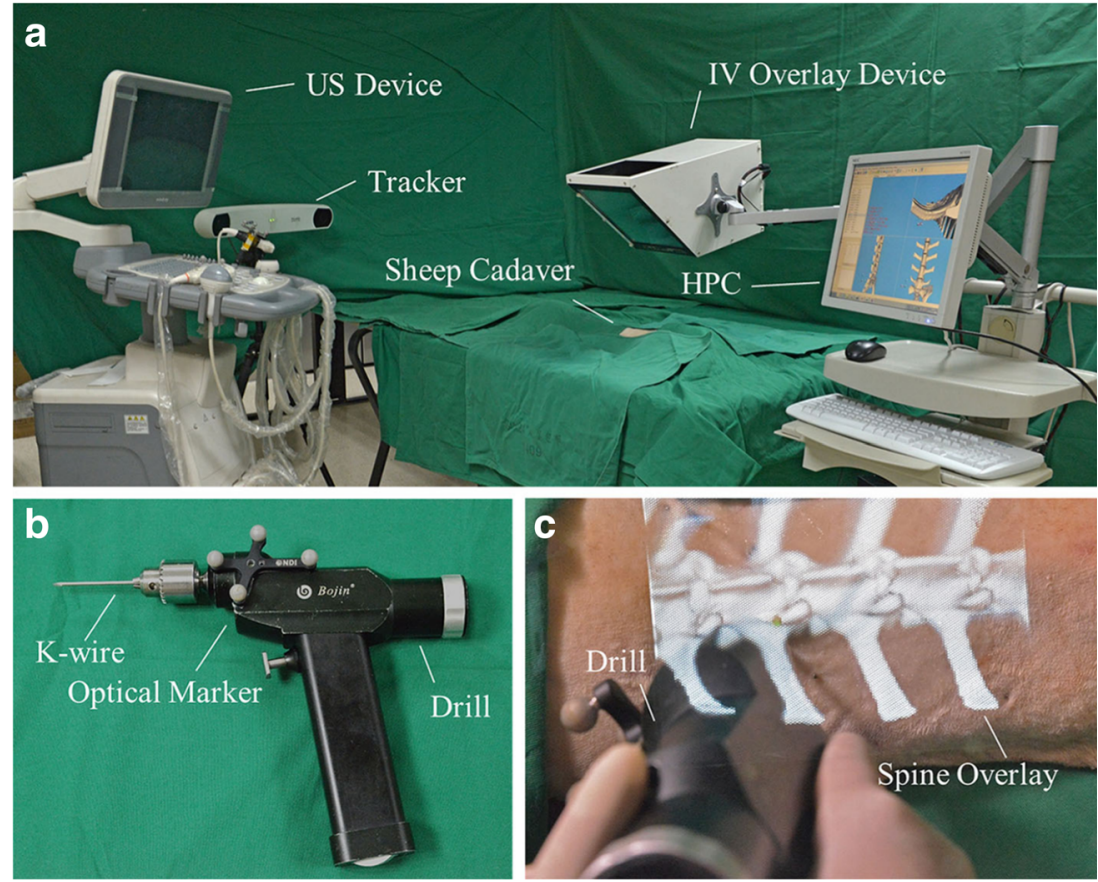

There were three studies comparing AR navigation to FH, with or without fluoroscopy, for spinal procedures other than pedicle screw placement. In a randomized controlled trial, Auloge et al. compared the accuracy of the pedicle cannulation phase in percutaneous vertebroplasty between two groups of 10 patients each, one using AR and the other FH with fluoroscopy [2]. They found no significant difference between the groups. In a similar setup, Wei et al. performed a randomized controlled trial on percutaneous kyphoplasty comparing HMD-AR to FH with fluoroscopy [46]. No accuracies were reported, but clinical outcomes differed significantly. The AR group had larger amounts of bone cement injected, increased postoperative vertebral height, and lower patient reported pain, 1 year postoperatively ( $p<0.05$ for all). Wanivenhaus et al. evaluated the benefit of AR for manual rod bending [45]. When comparing unassisted rod bending to using AR to display patient-adapted holographic rods to guide surgeons, time spent on bending and inserting the rod was significantly shorter with AR assistance (AR: $374 \pm 79$ vs. unassisted: $465 \pm 121 \mathrm{~s}, p=0.012$ ). Rod length was also significantly more often correct with AR (AR: $15 / 18$ vs. unassisted: $4 / 18, p<0.001$ ).

Only one study compared AR navigation to other modalities of navigated spine surgery. Müller et al. used an HMDAR device to place pedicle screws [37]. The control group consisted of patients treated using a widely available posetracking system (PTS) based on infrared cameras. There were no significant differences in translational errors (AR: $3.4 \pm$ $1.6 \mathrm{~mm}$ vs. PTS: $3.2 \pm 2.0 \mathrm{~mm}, p=0.85$ ) or angular errors (AR: $4.3 \pm 2.3^{\circ}$ vs. PTS: $3.5 \pm 1.4^{\circ}, p=0.30$ ).

\section{Workflow}

Three studies reported shorter and one longer operating times when using AR compared to FH with or without fluoroscopy $[2,32,45,46]$. Ten studies reported favorable impact on surgical time but lacked controls, or reported qualitatively positive workflow results for AR navigation $[11,13,20,21,23$, $30,36,38,42]$.

\section{Radiation dose}

All studies reporting on radiation doses used either intraoperative $\mathrm{CT}$ or intraoperative $\mathrm{CBCT}$ for patient registration (Table 2). No study relying on preoperative $\mathrm{CT}$ or intraoperative fluoroscopy for patient registration reported radiation doses.

One study compared AR navigation with CBCT patient registration to $\mathrm{FH}$ with fluoroscopy, and found that AR navigation resulted in significantly lower dose-area product (AR: $182.6 \pm 106.7 \mathrm{mGy} \mathrm{cm}{ }^{2}$ vs. FH: $367.8 \pm 184.7 \mathrm{mGy} \mathrm{cm}^{2}, p=$ 0.025 ) and fluoroscopy time (AR: $5.2 \pm 2.6 \mathrm{~s}$ vs. FH: $10.4 \pm$ $4.1 \mathrm{~s}, p=0.005)$ [2].

Five studies using either intraoperative CT or CBCT for patient registration reported effective dose, with means between $0.22 \pm 0.16 \mathrm{mSv}$ (cervical) and $15.8 \pm 1.8 \mathrm{mSv}$ (thoracolumbar) [10-13, 17]. Four of those studies were based partially, or in whole, on the same patient cohort, however [10-13]. Two studies using intraoperative CBCT for patient registration highlighted that staff radiation was null or negligible, due to being fully shielded while using radiation or because none was used intraoperatively $[17,38]$. 
Table 2 Studies reporting radiation doses

\begin{tabular}{|c|c|c|c|c|c|c|}
\hline Authors & Year & $\begin{array}{l}\text { Patient } \\
\text { registration } \\
\text { type }\end{array}$ & Surgical procedure & $\begin{array}{l}\text { Radiation including } \\
\text { postoperative } \\
\text { verification }\end{array}$ & Radiation dose to patient & Radiation dose to staff \\
\hline $\begin{array}{l}\text { Auloge } \\
\text { et al. } \\
\text { [2] }\end{array}$ & 2019 & $\begin{array}{l}\text { CBCT } \\
\text { Intraop }\end{array}$ & Vertebroplasty, 1 level & No & $\begin{array}{l}\text { DAP: } 182.6 \pm 106.7 \\
\text { mGy. } 71^{2}\end{array}$ & $\mathrm{n} / \mathrm{a}$ \\
\hline $\begin{array}{l}\text { Carl et al. } \\
{[10]^{*}}\end{array}$ & 2019 & CT Intraop & Variable, 1-2 vertebral levels* & No & $\begin{array}{l}\text { ED, mean dose: } \\
\text { Cervical: } 0.52 \mathrm{mSv} \\
\text { Thoracic: } 6.14 \mathrm{mSv} \\
\text { Lumbar: } 2.99 \mathrm{mSv}\end{array}$ & $\mathrm{n} / \mathrm{a}$ \\
\hline $\begin{array}{l}\text { Carl et al. } \\
{[11]^{*}}\end{array}$ & 2019 & CT Intraop & Intradural spinal lesions, $1-4$ levels* & No & $\begin{array}{l}\text { ED, mean dose: } \\
\text { Cervical: } 0.22 \pm 0.16 \mathrm{mSv} \\
\text { Thoracic: } 1.68 \pm 0.61 \mathrm{mSv}\end{array}$ & $\mathrm{n} / \mathrm{a}$ \\
\hline $\begin{array}{l}\text { Carl et al. } \\
{[13]^{*}}\end{array}$ & 2019 & CT Intraop & $\begin{array}{l}\text { Extra- and intradural spinal lesions, } \\
5-13 \text { levels* }\end{array}$ & No & $\begin{array}{l}\text { ED, range (min-max): } \\
\text { Cervical: } 0.35 \text { radur } \mathrm{mSv} \\
\text { Thoracic: } 2.16 \text { radur } \mathrm{mSv} \\
\text { Lumbar: } 3.5516 \mathrm{rad} \mathrm{mSv}\end{array}$ & $\mathrm{n} / \mathrm{a}$ \\
\hline $\begin{array}{c}\text { Carl et al. } \\
{[12]^{*}}\end{array}$ & 2020 & CT Intraop & $\begin{array}{l}\text { Extra- and intradural lesions, } \\
\text { degenerative, infections, and } \\
\text { deformities* }\end{array}$ & No & $\begin{array}{l}\text { ED, mean dose: } \\
\text { Cervical: } 0.29 \pm 0.17 \mathrm{mSv} \\
\text { Thoracic: } 3.40 \pm 2.38 \\
\text { mSv } \\
\text { Lumbar } 3.05 \pm 0.89 \mathrm{mSv}\end{array}$ & $\mathrm{n} / \mathrm{a}$ \\
\hline $\begin{array}{l}\text { Edstrom } \\
\text { et al. } \\
\text { [17] }\end{array}$ & 2020 & $\begin{array}{l}\text { CBCT } \\
\text { Intraop }\end{array}$ & Mainly scoliosis, $2-12$ levels & Yes & ED, average: $15.8 \pm 1.8 \mathrm{mSv}$ & $\begin{array}{l}\text { Staff dose, average: } 0.21 \pm \\
0.06 \mu \mathrm{Sv}\end{array}$ \\
\hline $\begin{array}{l}\text { Peh et al. } \\
\text { [38] }\end{array}$ & 2020 & $\begin{array}{l}\text { CBCT } \\
\text { Intraop }\end{array}$ & Cadaveric pedicle screw placement & Yes & $\mathrm{n} / \mathrm{a}$ & $\begin{array}{l}\text { "The performing surgeon } \\
\text { was not exposed to } \\
\text { radiationt }\end{array}$ \\
\hline
\end{tabular}

$C B C T$ cone beam computed tomography, $C T$ computed tomography, $D A P$ dose-area product, $E D$ effective dose

*A large share of patients has been re-used in these studies

\section{Cost-benefit}

No included study provided cost-benefit analyses of using AR navigation or discussed costs and benefits in quantitative terms.

\section{Discussion}

The use of AR navigation in spine surgery represents a meaningful improvement over existing CAS technologies concerning workflow and ease-of-use and is favorable to FH surgery in terms of accuracy and radiation exposure. AR systems have demonstrated a high accuracy compared to FH surgery in several clinical studies. Notably, all studies involving pedicle screw placement accuracy that reported favorable results for AR relied on Monitor-AR. HMD-AR was either comparable or inferior to FH surgery for pedicle screw placement. This may be explained by the fact that HMD systems are comparatively newer and have one additional tracked object (the HMD itself), thereby increasing the complexity and potential for errors. Another explanation could be that all Monitor-AR included in this systematic review relies on intraoperative $\mathrm{CBCT}$ and skin markers for patient registration and tracking, while most HMD-AR relies on manual registration and direct patient surface tracking. When using manual registration and direct surface tracking, the AR image is manually adjusted to match the reality thereby inducing a potential registration error. Intraoperative imaging in combination with optical markers or a DRF, however, allows for an accurate automatic coregistration $[7,10]$. Nonetheless, an isolated comparison between Monitor-AR and HMD-AR on the one hand, and optical markers and surface tracking on the other hand, cannot be performed on the currently available data.

An ideal navigation system for spine surgery should provide a clear interface highlighting only what is important and an unobtrusive patient tracking with high fault-tolerance. Proponents of HMD-AR may argue that it will represent the optimal user experience once the technology is matured, provided it reaches an acceptable accuracy. If the HMD device is unobtrusive and lightweight and offers a wide field of view, having the AR overlay directly in the surgeon's view could be an advantage. However, HMD may increase the risk for inattentional blindness compared to monitors [15]. Nonetheless, as long as accuracy, bulkiness, or other practical factors inhibit this end-goal, Monitor-AR may be the better alternative. The advantage of a monitor is that the surgeon can perform other tasks in the OR that do not require navigation, without being disturbed by a head piece. The results of this systematic review are not conclusive regarding the best interface. 
In this systematic review, the impact of AR navigation on radiation exposure for both patients and staff were favorable compared to FH. Given that AR principally concerns presentation of imaging data, the radiation exposure is expected to be comparable to other CAS solutions. However, improved workflow may reduce staff exposure, while increased accuracy may reduce the need for additional imaging.

Notably, no study provided any cost-benefit analyses of using AR navigation. However, the financial benefits of navigation were presented in a recent review indicating that using navigation results in "buying-back" the investment in the long term [26]. There is no reason for AR systems to deviate from this pattern. In the future, it will be paramount to include financial evaluations of each system studied.

\section{Future perspectives}

An ideal spinal navigation system should provide a timeefficient setup and registration, be easy to use, and allow visualization of the anatomy without distracting the surgeon or obscuring the surgical field $[25,26]$. The system must be accurate and preferably offer the possibility to confirm the results. AR navigation offers a solution to increase the easeof-use while allowing an unobtrusive visualization of the anatomy. Using optical markers or surface recognition for patient tracking simplifies the setup and registration process.

The obtained technical accuracy by AR is already relatively high. The challenge is to achieve maximal accuracy also in complex cases. By including AR tracking of the surgical tools, a more direct feedback could be achieved [8]. Moreover, surgical accuracy could be markedly improved by replacing the human hand with a robotic arm. Initial studies on AR navigation combined with robotics demonstrate a significantly higher accuracy than AR without the robot $[4,5]$. Automatization of parts of the process using AI or machine learning could both improve workflow and simplify robotic integration [6].

To further improve surgical results, AR navigation could be combined with sensing technologies such as impedance probes or optical probes relying on diffuse reflectance spectroscopy (DRS) [9, 39]. These, and similar, technologies could provide direct feedback on the tissue type where the tip of the surgical tool or screws are located and possibly be integrated in an automated workflow.

Arguably, it is only a matter of time until technological achievements transferred to spine surgery will have the upper hand in terms of accuracy in identifying static anatomical landmarks and eventually also dynamic or moving surgical targets. The boundaries between what can and what cannot be done with computer assistance, robotics, and $\mathrm{AI}$ in surgery will primarily be defined by medico-legal concerns rather than technological. However, for a foreseeable time, the surgical handicraft needed for decompression and microneurosurgical handling of intrathecal nervous system tissues will be reserved for the surgeon. Nonetheless, AR visualization may provide the surgeon with valuable assistance in the performance of these delicate maneuvers.

\section{Limitations}

AR in spine surgery is a relatively new concept reflected in the limited number of publications. Most included studies were non-controlled or non-randomized, which could introduce a potential bias in the study outcomes and conclusions. Only one RCT was identified in our systematic review. Only one study was publicly registered before beginning the trial and no additional studies could be found by the authors of this review on clinicaltrials.gov, meaning the ability to objectively evaluate publication bias is currently lacking.

\section{Conclusions}

AR provides a meaningful addition to FH surgery and traditional navigation methods for spine surgery. By enhancing the surgical field with radiological guidance information, the surgeon's attention is kept on the surgical field. In this systematic review, superior workflow and non-inferior accuracy were the main findings when comparing AR to $\mathrm{FH}$ or conventional navigation techniques. A limited number of studies indicated decreased radiation dose for both patients and staff.

Future developmental efforts should be focused on further improving the AR system setups regarding workflow optimization and choice of the method to present virtual information. Future studies on the impact on clinical outcomes such as patient mortality, morbidity, and complications are required.

Funding Open access funding provided by Karolinska Institute.

\section{Compliance with ethical standards}

Conflict of interest Karolinska University Hospital has a major collaboration agreement with Philips Healthcare concerning research. The authors declare that they have no conflicts of interest.

Open Access This article is licensed under a Creative Commons Attribution 4.0 International License, which permits use, sharing, adaptation, distribution and reproduction in any medium or format, as long as you give appropriate credit to the original author(s) and the source, provide a link to the Creative Commons licence, and indicate if changes were made. The images or other third party material in this article are included in the article's Creative Commons licence, unless indicated otherwise in a credit line to the material. If material is not included in the article's Creative Commons licence and your intended use is not permitted by statutory regulation or exceeds the permitted use, you will need to obtain permission directly from the copyright holder. To view a copy of this licence, visit http://creativecommons.org/licenses/by/4.0/. 


\section{References}

1. Abe Y, Sato S, Kato K, Hyakumachi T, Yanagibashi Y, Ito M, Abumi K (2013) A novel 3D guidance system using augmented reality for percutaneous vertebroplasty: technical note. J Neurosurg Spine 19:492-501. https://doi.org/10.3171/2013.7.Spine12917

2. Auloge P, Cazzato RL, Ramamurthy N, de Marini P, Rousseau C, Garnon J, Charles YP, Steib JP, Gangi A (2019) Augmented reality and artificial intelligence-based navigation during percutaneous vertebroplasty: a pilot randomised clinical trial. Eur Spine J. https://doi.org/10.1007/s00586-019-06054-6

3. Azuma R, Baillot Y, Behringer R, Feiner S, Julier S, MacIntyre B (2001) Recent advances in augmented reality. IEEE Comput Graph Appl 21:34-47

4. Balicki M, Kyne S, Toporek G, Holthuizen R, Homan R, Popovic A, Burström G, Persson O, Edström E, Terander AE (2020) Design and control of an image guided robot for spine surgery in a hybrid OR. Int J Med Rob Comput Assisted Surg 16:e2108. https://doi. org $/ 10.1002 /$ rcs. 2108

5. Burström G, Balicki M, Patriciu A, Kyne S, Popovic A, Holthuizen R, Homan R, Skulason H, Persson O, Edström E, Elmi-Terander A (2020) Feasibility and accuracy of a robotic guidance system for navigated spine surgery in a hybrid operating room: a cadaver study. Sci Rep 10:7522. https://doi.org/10.1038/s41598-02064462-x

6. Burström G, Buerger C, Hoppenbrouwers J, Nachabe R, Lorenz C, Babic D, Homan R, Racadio JM, Grass M, Persson O, Edström E, Elmi Terander A (2019) Machine learning for automated 3dimensional segmentation of the spine and suggested placement of pedicle screws based on intraoperative cone beam computer tomography. J Neurosurg Spine 31:147-154. https://doi.org/10. 3171/2018.12.Spine181397

7. Burström G, Nachabe R, Homan R, Hoppenbrouwers J, Holthuizen R, Persson O, Edström E, Elmi-Terander A (2020) Frameless patient tracking with adhesive optical skin markers for augmented reality surgical navigation in spine surgery Spine. Spine (Phila Pa 1976) 45:1598-1604. https://doi.org/10.1097/BRS. 0000000000003628

8. Burström G, Nachabe R, Persson O, Edstrom E, Elmi Terander A (2019) Augmented and virtual reality instrument tracking for minimally invasive spine surgery: a feasibility and accuracy study. Spine (Phila Pa 1976) 44:1097-1104. https://doi.org/10.1097/ BRS.0000000000003006

9. Burström G, Swamy A, Spliethoff JW, Reich C, Babic D, Hendriks BH, Skulason H, Persson O, Terander AE, Edström E (2019) Diffuse reflectance spectroscopy accurately identifies the precortical zone to avoid impending pedicle screw breach in spinal fixation surgery. Biomed Opt Express 10:5905-5920. https://doi. org/10.1364/BOE.10.005905

10. Carl B, Bopp M, Sass B, Nimsky C (2019) Microscope-based augmented reality in degenerative spine surgery: initial experience. World Neurosurg 128:E541-E551. https://doi.org/10.1016/j. wneu.2019.04.192

11. Carl B, Bopp M, Sass B, Pojskic M, Nimsky C (2019) Augmented reality in intradural spinal tumor surgery. Acta Neurochir. https:// doi.org/10.1007/s00701-019-04005-0

12. Carl B, Bopp M, Sass B, Pojskic M, Voellger B, Nimsky C (2020) Spine surgery supported by augmented reality. Global Spine J 10: 41S-55S. https://doi.org/10.1177/2192568219868217

13. Carl B, Bopp M, Sass B, Voellger B, Nimsky C (2019) Implementation of augmented reality support in spine surgery. Eur Spine J 28:1697-1711. https://doi.org/10.1007/s00586-01905969-4

14. Dennler C, Jaberg L, Spirig J, Agten C, Gotschi T, Furnstahl P, Farshad M (2020) Augmented reality-based navigation increases precision of pedicle screw insertion. J Orthop Surg Res 15:174. https://doi.org/10.1186/s13018-020-01690-x

15. Dixon BJ, Daly MJ, Chan HH, Vescan A, Witterick IJ, Irish JC (2014) Inattentional blindness increased with augmented reality surgical navigation. Am J Rhinol Allergy 28:433-437

16. Edström E, Burström G, Nachabe R, Gerdhem P, Elmi Terander A (2020) A novel augmented-reality-based surgical navigation system for spine surgery in a hybrid operating room: design, workflow, and clinical applications. Oper Neurosurg (Hagerstown) 18:496-502. https://doi.org/10.1093/ons/opz236

17. Edström E, Burström G, Omar A, Nachabe R, Söderman M, Persson O, Gerdhem P, Elmi-Terander A (2020) Augmented reality surgical navigation in spine surgery to minimize staff radiation exposure. Spine (Phila Pa 1976) 45:E45-E53. https://doi.org/10. 1097/BRS.0000000000003197

18. Edström E, Burström G, Persson O, Charalampidis A, Nachabe R, Gerdhem P, Elmi-Terander A (2020) Does augmented reality navigation increase pedicle screw density compared to free-hand technique in deformity surgery? Single surgeon case series of 44 patients. Spine (Phila Pa 1976) 45:E1085-E1090. https://doi.org/10. 1097/BRS.0000000000003518

19. Elmi-Terander A, Burström G, Nachabe R, Fagerlund M, Stahl F, Charalampidis A, Edström E, Gerdhem P (2020) Augmented reality navigation with intraoperative $3 \mathrm{D}$ imaging vs fluoroscopyassisted free-hand surgery for spine fixation surgery: a matchedcontrol study comparing accuracy. Sci Rep 10:707. https://doi. org/10.1038/s41598-020-57693-5

20. Elmi-Terander A, Burström G, Nachabe R, Skulason H, Pedersen K, Fagerlund M, Ståhl F, Charalampidis A, Söderman M, Holmin S, Babic D, Jenniskens I, Edström E, Gerdhem P (2019) Pedicle screw placement using augmented reality surgical navigation with intraoperative 3D imaging: a first in-human prospective cohort study. Spine (Phila Pa 1976) 44:517-525. https://doi.org/10.1097/ BRS.0000000000002876

21. Elmi-Terander A, Nachabe R, Skulason H, Pedersen K, Soderman M, Racadio J, Babic D, Gerdhem P, Edstrom E (2018) Feasibility and accuracy of thoracolumbar minimally invasive pedicle screw placement with augmented reality navigation technology. Spine (Phila Pa 1976) 43:1018-1023. https://doi.org/10.1097/BRS. 0000000000002502

22. Elmi-Terander A, Skulason H, Soderman M, Racadio J, Homan R, Babic D, van der Vaart N, Nachabe R (2016) Surgical navigation technology based on augmented reality and integrated 3D intraoperative imaging: a spine cadaveric feasibility and accuracy study. Spine (Phila Pa 1976) 41:E1303-E1311. https://doi.org/10.1097/ BRS.0000000000001830

23. Gibby JT, Swenson SA, Cvetko S, Rao R, Javan R (2019) Headmounted display augmented reality to guide pedicle screw placement utilizing computed tomography. Int J Comput Assist Radiol Surg 14:525-535. https://doi.org/10.1007/s11548-018-1814-7

24. Grading quality of evidence and strength of recommendations (2004) BMJ 328:1490. https://doi.org/10.1136/bmj.328.7454.1490

25. Hartl R, Lam KS, Wang J, Korge A, Kandziora F, Audige L (2013) Worldwide survey on the use of navigation in spine surgery. World Neurosurg 79:162-172. https://doi.org/10.1016/j.wneu.2012.03. 011

26. Hussain I, Cosar M, Kirnaz S, Schmidt FA, Wipplinger C, Wong T, Härtl R (2020) Evolving navigation, robotics, and augmented reality in minimally invasive spine surgery. Global Spine J 10:22S33S. https://doi.org/10.1177/2192568220907896

27. Jud L, Fotouhi J, Andronic O, Aichmair A, Osgood G, Navab N, Farshad M (2020) Applicability of augmented reality in orthopedic surgery-a systematic review. BMC Musculoskelet Disord 21. https://doi.org/10.1186/s12891-020-3110-2

28. Kipper G, Rampolla J (2012) Augmented reality: an emerging technologies guide to AR. Elsevier, Amsterdam 
29. Liberati A, Altman DG, Tetzlaff J, Mulrow C, Gøtzsche PC, Ioannidis JP, Clarke M, Devereaux PJ, Kleijnen J, Moher D (2009) The PRISMA statement for reporting systematic reviews and meta-analyses of studies that evaluate health care interventions: explanation and elaboration. Ann Intern Med 151:W-65-W-94

30. Liebmann F, Roner S, von Atzigen M, Scaramuzza D, Sutter R, Snedeker J, Farshad M, Furnstahl P (2019) Pedicle screw navigation using surface digitization on the Microsoft HoloLens. Int $\mathrm{J}$ Comput Assist Radiol Surg 14:1157-1165. https://doi.org/10. 1007/s11548-019-01973-7

31. Liu H, Wu J, Tang Y, Li H, Wang W, Li C, Zhou Y (2019) Percutaneous placement of lumbar pedicle screws via intraoperative CT image-based augmented reality-guided technology. J Neurosurg Spine 1-6. https://doi.org/10.3171/2019.10.Spine19969

32. Liu H, Wu JL, Tang Y, Li HY, Wang WK, Li CQ, Zhou Y (2020) Percutaneous placement of lumbar pedicle screws via intraoperative CT image-based augmented reality-guided technology. J Neurosurg Spine 32:542-547. https://doi.org/10.3171/2019.10. Spine19969

33. Ma L, Zhao Z, Chen F, Zhang B, Fu L, Liao H (2017) Augmented reality surgical navigation with ultrasound-assisted registration for pedicle screw placement: a pilot study. Int J Comput Assist Radiol Surg 12:2205-2215. https://doi.org/10.1007/s11548-017-1652-z

34. Meola A, Cutolo F, Carbone M, Cagnazzo F, Ferrari M, Ferrari V (2017) Augmented reality in neurosurgery: a systematic review. Neurosurg Rev 40:537-548. https://doi.org/10.1007/s10143-0160732-9

35. Molina CA, Phillips FM, Colman MW, Ray WZ, Khan M, Orru E, Poelstra K, Khoo L (2020) A cadaveric precision and accuracy analysis of augmented reality-mediated percutaneous pedicle implant insertion. J Neurosurg Spine 1-9. https://doi.org/10.3171/ 2020.6.Spine20370

36. Molina CA, Theodore N, Ahmed AK, Westbroek EM, Mirovsky Y, Harel R, Orru E, Khan M, Witham T, Sciubba DM (2019) Augmented reality-assisted pedicle screw insertion: a cadaveric proof-of-concept study. J Neurosurg Spine 1-8. https://doi.org/10. 3171/2018.12.SPINE181142

37. Muller F, Roner S, Liebmann F, Spirig JM, Furnstahl P, Farshad M (2020) Augmented reality navigation for spinal pedicle screw instrumentation using intraoperative 3D imaging. Spine J 20:621628. https://doi.org/10.1016/j.spinee.2019.10.012

38. Peh S, Chatterjea A, Pfarr J, Schafer JP, Weuster M, Kluter T, Seekamp A, Lippross S (2020) Accuracy of augmented reality surgical navigation for minimally invasive pedicle screw insertion in the thoracic and lumbar spine with a new tracking device. Spine J 20:629-637. https://doi.org/10.1016/j.spinee.2019.12.009

39. Guillen PT, Knopper RG, Kroger J, Wycliffe ND, Danisa OA, Cheng WK (2014) Independent assessment of a new pedicle probe and its ability to detect pedicle breach: a cadaveric study. J Neurosurg Spine 21:821-825. https://doi.org/10.3171/2014.6. spine131028

40. Siemionow KB, Katchko KM, Lewicki P, Luciano CJ (2020) Augmented reality and artificial intelligence-assisted surgical navigation: technique and cadaveric feasibility study. J Craniovertebr Junction Spine 11:81-85. https://doi.org/10.4103/jcvjs.JCVJS 48 20

41. Tian NF, Huang QS, Zhou P, Zhou Y, Wu RK, Lou Y, Xu HZ (2011) Pedicle screw insertion accuracy with different assisted methods: a systematic review and meta-analysis of comparative studies. Eur Spine J 20:846-859. https://doi.org/10.1007/s00586$010-1577-5$

42. Urakov TM, Wang MY, Levi AD (2019) Workflow caveats in augmented reality-assisted pedicle instrumentation: cadaver lab. World Neurosurg. https://doi.org/10.1016/j.wneu.2019.03.118

43. Verhey JT, Haglin JM, Verhey EM, Hartigan DE (2020) Virtual, augmented, and mixed reality applications in orthopedic surgery. Int J Med Robot 16:e2067. https://doi.org/10.1002/rcs.2067

44. von Atzigen M, Liebmann F, Hoch A, Bauer DE, Snedeker JG, Farshad M, Fürnstahl P (2020) HoloYolo: a proof-of-concept study for marker-less surgical navigation of spinal rod implants with augmented reality and on-device machine learning. Int J Med Robot e2184. https://doi.org/10.1002/rcs.2184

45. Wanivenhaus F, Neuhaus C, Liebmann F, Roner S, Spirig JM, Farshad M (2019) Augmented reality-assisted rod bending in spinal surgery. Spine J 19:1687-1689. https://doi.org/10.1016/j.spinee. 2019.06.019

46. Wei P, Yao Q, Xu Y, Zhang H, Gu Y, Wang L (2019) Percutaneous kyphoplasty assisted with/without mixed reality technology in treatment of OVCF with IVC: a prospective study. J Orthop Surg Res 14:255. https://doi.org/10.1186/s13018-019-1303-x

47. Wu JR, Wang ML, Liu KC, Hu MH, Lee PY (2014) Real-time advanced spinal surgery via visible patient model and augmented reality system. Comput Methods Prog Biomed 113:869-881. https://doi.org/10.1016/j.cmpb.2013.12.021

Publisher's note Springer Nature remains neutral with regard to jurisdictional claims in published maps and institutional affiliations. 